Makalenin Türü / Article Type Geliș Tarihi / Date Received Kabul Tarihi / Date Accepted Yayın Tarihi / Date Published
: Araștırma Makalesi / Researh Article

: 02.07.2019

: 07.08.2019

$\cdot 11.10 .2019$

\title{
MESLEKİ KARAR ENVANTERİ FAKTÖR YAPISINA AİT FARKLI ÖLÇME MODELLERININ DOĞRULAYICI FAKTÖR ANALIZİ İLE İNCELENMESİ
}

\author{
Funda NALBANTOĞLU YILMAZ ${ }^{1}$
}

ÖZ

$\mathrm{Bu}$ araştırmanın amacı, lise öğrencilerinin mesleki kararsızlık düzeylerini ölçmek için Çakır (2004) tarafında geliştirilen Mesleki Karar Envanterinin faktör yapısını farklı modeller çerçevesinde doğrulayıcı faktör analiziyle incelemektir. Mesleki Karar Envanterinin ön çalışmasında Çakır (2004) tarafından açımlayıcı faktör analizi ile envanterin faktör çözümlenmesi yapılmıștır. Envanterin geliștirilme aşamasında 5 faktör toplam 30 madde içeren formu ortaya konulmuştur. Bu araștırmada ise ön çalışmada ortaya konulan yapı tek boyut, ilişkili birinci düzey, ilişkisiz birinci düzey, ikinci düzey ve iki-faktör model olmak üzere 5 farklı model çerçevesinde doğrulayıcı faktör analizi ile test edilmiştir. Yapılan doğrulayıcı faktör analizlerinde, Mesleki Karar Envanterinin ikinci düzey yapısının bir model olarak doğrulandığı sonucuna ulaşılmıştır. Bu doğrultuda İçsel Çatışma, Kendini Yeterince Tanımama, Meslek ve Alan Bilgisi Eksikliği, Meslek Seçiminde Akılcı Olmayan İnançlar ve Dışsal Çatışmalar değişkenlerinin Mesleki Karar yapısını oluşturduğu söylenilebilir. Ayrıca genel yapı olan Mesleki Karar üzerinde en çok etkiye sahip değişkenin Meslek ve Alan Bilgisi Eksikliği olduğu belirlenmiştir. Envanter için hesaplanan ortalama açıklanan varyans ve yapı güvenirlik katsayıları da yeterli düzeydedir.

Anahtar Kelimeler: Mesleki karar, doğrulayıcı faktör analizi, birinci düzey, ikinci düzey, iki-faktör

\section{INVESTIGATING DIFFERENT MEASUREMENT MODELS OF CAREER DECISION INVENTORY FACTOR STRUCTURE WITH CONFIRMATORY FACTOR ANALYSIS}

\begin{abstract}
The goal of the study was to compare different models for Career Decision Inventory which was developed Çakır (2004) in confirmatory factor analysis. In the preliminary study of the Career Decision Inventory, Çakır (2004) conducted exploratory factor analysis of the inventory. At the stage of development of the inventory, a form consisting of 5 factors and 30 items was presented. In this study, the structure revealed in the preliminary study was tested with confirmatory factor analysis in five different models: unidimensional, correlated first-order, uncorrelated first-order, second-order and bifactor model. In the confirmatory factor analysis, it was concluded that the second-order structure of the Career Decision Inventory was confirmed as a model. In this direction, it can be said that the variables of Internal Conflicts, Lack of Self Knowledge, Lack of Occupation and Field Knowledge, Irrational Beliefs about Career Choice and External Conflicts constitute the Career Decision Structure. In addition, the most influential variable on the general structure of Career Decision was determined to be the Lack of Occupation and Field Knowledge. The construct reliability coefficients and average variance extracted calculated for the inventory were found to be sufficient.
\end{abstract}

Keywords: Career decision, confirmatory factor analyses, first-order, second-order, bi-factor

\footnotetext{
${ }^{1}$ Nevşehir Hacı Bektaş Veli Üniversitesi, Eğitim Fakültesi, fundan@nevsehir.edu.tr, 느tttps://orcid.org/0000-0002-3228-4605
} 


\section{GíRiş}

Davranış bilimlerinde, eğitim ve psikolojide bireylerin özelliklerinin belirlenmesinde ölçme araçları önemli bir yere sahiptir. Kullanılan ölçme aracının ölçtüğü yapının araştırılması ise aracın geçerlik kanıtları için önemli ve bir bakıma zorunluluktur.

Eğitim ve psikolojide ölçek geliştirme ve uyarlama çalışmalarında faktör analizi ölçme aracının ve verilerin yapısını ortaya çıkartarak araştırmacıya bir yol haritası sunması bakımından sıklıkla kullanılmaktadır.

Faktör analizi, ölçülmek istenen yapıyı, değişkenleri anlamaya yardımcı istatistiksel bir tekniktir. Ölçek geliştirme/uyarlama çalışmalarında faktör analizinin açımlayıcı (keşfedici) ve doğrulayıcı olmak üzere iki türü sıklıkla kullanılmaktadır. Açımlayıcı faktör analizinde (AFA), birbiriyle ilişkili değişkenleri bir araya getirerek veriyi tanımlamak ve özetlemek amaçlanır (Tabachnick ve Fidell, 2001). Her bir maddenin diğer hangi maddelerle gruplaştığ 1 ve bu gruplara ne derecede bağlandığı açımlayıcı faktör analizinin uygulama alanlarından biridir (Alpar, 2017). Doğrulayıcı faktör analizinde (DFA) ise araştırmacı verinin daha önce belirlenmiş olan faktör yapısı ile uyumlu olup olmadığını ortaya koymak ister (Meydan ve Şeşen, 2015). Doğrulayıcı faktör analizi, ortaya konulan yapının bir model olarak doğrulanıp doğrulanmadığını test eder. Kısaca, açımlayıcı faktör analizinde, gözlenen değişkenler yardımıyla verideki faktör yapısı belirlenmeye çalışılırken, doğrulayıcı faktör analizinde belirlenen kuramsal yapının veride var olup olmadığı test edilir (Alpar, 2017).

Pek çok ölçek geliştirme çalışmasında açımlayıcı ve doğrulayıcı faktör analizinin beraber kullanıldığı görülmektedir. Jöreskog ve Sörbom $(1993,22)$, Worthington \& Whittaker (2006) da yapılacak ölçek geliştirme çalışmalarda açımlayıcı faktör analizinin ardından doğrulayıcı faktör analizinin yapılmasını önermiş̧ir. Çünkü değişkenler arasındaki ilişkilerle ilgili ön bilgi olmadan doğrulayıcı faktör analizi yapmak uygun olmamaktadır. Açımlayıcı faktör analizinde ve kuramsal olarak belirlenen yapının farklı bir örneklemde doğrulayıcı faktör analizi ile test edilmesi ölçme aracının geçerlik kanıtları açısından önemlidir.

Literatürde de, ölçeklerin yapısının doğrulayıcı faktör analizi ile incelenmesi, hatta bu incelemede farklı modellerin karşılaştırılması ve veriye en uygun modelin belirlenmesi önerilmektedir (Byrne, 1998; Cucina ve Byle, 2017; Meydan ve Şeşen, 2015). Oysa literatürdeki ölçek geliştirme çalışmalarında sıklıkla birinci düzey DFA modelinin test edildiği/raporlandığı görülmektedir. Bilimsel araştırmanın doğası gereği, bir dizi değişken arasındaki ilişkilerin açıklanmasında birden fazla modelin geçerli sonuçlar verebilmesi olasıdır (Şimşek, 2007). Oysa bilimsel araştırma gereği söz konusu değişkenler açısından en iyi açıklamanın hangi model tarafından üretildiğine dair kanıtlar sunulmalıdır (Şimşek, 2007). Bu doğrultuda araştırmacılar ölçeklerin yapı geçerliğine kanıt ararken sadece birinci düzey DFA değil, birden fazla modeli (birinci düzey, ikinci düzey, iki-faktör model vb.) test etmeli ve en uygun modeli belirlemelidir. Bu doğrultuda araştırmada Çakır (2004) tarafından geliştirilen Mesleki Karar Envanteri (MKE) ele alınmış ve bu envanterin faktör yapısı DFA ile birden fazla model (birinci düzey, ikinci düzey, iki-faktör model vb.) çerçevesinde incelenmiştir.

Günümüz problemlerinden biri de yaşanılan kararsızlıklar ve bu kararsızlıkların hayatlara etkisi olmuştur. Önemli mesleki kararların verildiği yıllarda öğrencilerin tercih/seçim yapmalarında mesleki kararsızlık yaşamaları olasıdır. Farklı etkiler sebebiyle istenmeyen tercihlerin yapılması bireyleri mutsuz etmekte, hayatlarında geri dönülemez etkiler yaratmaktadır. Bu nedenle meslek, alan, branş seçimleri öncesinde öğrencilerin kararsızlık durumlarını belirlemek/araştırmak, kararsızlıklarında etkili olan değişkenleri belirlemek ve bu doğrultuda rehberlik programları uygulamak önemlidir. Türkçe alan yazında lise öğrencilerinin mesleki kararsızlık durumlarını incelemede kullanılabilecek araç ise sınırlıdır. Bu sınırlılık nedeniyle de Çakır (2004) tarafından Mesleki Karar envanteri geliştirilmiştir. Geliştirilen Mesleki Karar envanteri, lise öğrencilerinin mesleki kararsızlık durumlarını belirlemek için kullanılan ve kullanılabilecek önemli araçlardan biridir.

Çakır (2004), envanterin geliştirme aşamasında faktör yapısını belirlemek için açımlayıcı faktör analizi kullanmıştır. Araştırmacı tarafından envanterin geliştirilme aşamasında yapılan açımlayıcı faktör analizinde 30 maddenin 5 faktör altında toplandığı belirlenmiștir. Bu doğrultuda envanter, hem literatür hem de açımlayıcı faktör analizi sonuçlarına göre öğrencilerin mesleki kararsızlık yaşamalarında etki eden içsel çatışmalar (1), kendini yeterince tanımama (2), meslek ve alan bilgisi eksikliği (3), meslek seçimine ilişkin akılcı olmayan inançlar (4), dışsal çatışmalar (5) değişkenlerini içermektedir. Bu araştırmada ise envanterin faktör yapısı araştırmacının çalışmasındaki açımlayıcı faktör analizi sonucu doğrultusunda kurulan farklı modeller (tek faktör, ilişkisiz birinci düzey, ilişkili birinci düzey, ikinci düzey ve iki-faktör model) çerçevesinde, envanterin geliştirilme aşamasından farklı bir gruptan elde edilen verilerle doğrulayıcı faktör analizi ile incelenmiş ve sonuçlar tartışılmıştır. $\mathrm{Bu}$ doğrultuda araştırmada, Mesleki Karar Envanterinin faktör yapısının açımlayıcı faktör analizine ek olarak farklı modeller üzerinden doğrulayıcı faktör analizi ile test edilmesi ve en uygun modelin belirlenmesi amaçlanmaktadır. $\mathrm{Bu}$ yönüyle araştırmanın alan yazına hem Mesleki Karar envanterine ilişkin güvenirlik ve geçerlik ek kanıtları sağlaması, hem de ölçek geliştirme/uyarlama çalışmalarında üst düzey doğrulayıcı faktör analizlerinin kullanımı, birinci düzey modeller haricinde üst düzey modellerin kullanımı gibi açılardan katkı sağlaması beklenmektedir. 


\section{YÖNTEM}

\subsection{Araştırma Modeli}

Mesleki Karar envanterinin faktör yapısının birinci düzey, ikinci düzey ve iki-faktör modeller çerçevesinde incelendiği bu araştırma tarama modelindedir.

\section{2. Çalışma Grubu}

Araştırma Nevşehir merkezinde bulunan liselerdeki 467 öğrenciden elde edilen veriler üzerinden gerçekleştirilmiştir. Araştırmaya katılan öğrenciler 11 ve 12. sınıfta olup 16-18 yaş aralığına sahiptir. Literatürde DFA analizinde serbest parametre sayısının 5 katı (Bentler ve Chou, 1987), 10 katı (Bentler ve Chou, 1987; Kline, 2016; Moshagen ve Musch, 2014) örneklem büyüklüğünün uygun olduğu belirtilmiştir. Robust en çok olabilirlik kestirimi için en az 400 örneklem büyüklüğü önerilmektedir (Boomsma ve Hoogland, 2001; Schermelleh-Engel, Moosbrugger ve Müller, 2003). Bu doğrultuda katılımcı sayısının yapılacak analiz kapsamında yeterli olduğu söylenebilir.

\section{3. Ölçme Aracı}

Mesleki Karar Envanteri, lise öğrencilerinin mesleki kararsızlık durumunu araştırmak için kullanılmaktadır. MKE, "İçsel Çatışmalar (İçsel)", "Kendini Yeterince Tanımama (Tanımama)", "Meslek ve Alan Bilgisi Eksikliği (Eksiklik)", "Meslek Seçimine İlişkin Akılcı Olmayan İnançlar (İnanç)", "Dışsal çatışmalar (Dışsal)” olmak üzere beş faktörden oluşmaktadır. Envanterde toplam 30 madde bulunmaktadır. Çakır (2004), tarafından envanterin geliştirilme aşamasında yapılan çalışmada envanterin İçsel çatışmalar faktöründe 8, kendini yeterince tanımama 7, meslek ve alan bilgisi eksikliği 7, meslek seçimine ilişkin akılcı olmayan inançlar 4 ve dışsal çatışmalar kısmında 4 madde bulunmaktadır. Maddeler 5'li Likert biçiminde cevaplanmaktadır. Envanterden alınan yüksek puan öğrencilerin mesleki kararsızlığını göstermektedir.

Envanterin geliştirilme aşamasında Cronbach Alfa güvenirlik katsayısı 0.85 ve test tekrar test güvenirliği 0.83 olarak hesaplanmıştır (Çakır, 2004). Bu araştırmadaki verilerle ise güvenirlik tekrar hesaplanmış ve envantere ait Cronbach Alfa güvenirlik katsayısı envanter için 0.93, içsel için 0,87, tanımama için 0,81, eksiklik için 0,80, inanç için 0,70 ve dişsal faktörü için 0,70 bulunmuştur.

\subsection{Verilerin Analizi}

Lise öğrencilerinin mesleki kararsızlık düzeylerini ölçmek için Çakır (2004) tarafında geliştirilen Mesleki Karar Envanterinin ön çalışmasında açımlayıcı faktör analizi envanterin faktör yapısı belirlenmiştir. Bu araştırmada Mesleki Karar Envanterinin belirlenen faktör yapısının farklı modeller üzerinden doğrulayıcı faktör analizi ile test edilmesi ve en iyi modelin belirlenmesi amaçlanmaktadır. Byrne (1998), doğrulayıcı faktör analizinde tek faktör, birinci düzey ve ikinci düzey olmak üzere farklı modellerin test edilebileceğini belirtmiştir. Bu doğrultuda araştırma Şekil 1'de belirtilen modeller çerçevesinde yürütülmüştür.

Şekil 1'de verilen ve araştırma kapsamında incelenen modellerden; Model 1 tek faktör-tek boyut modeldir. Tek faktör model, tüm maddelerin tek bir faktör altında toplandığ 1 model olarak tanımlanabilir. Model 2, faktörler arasında ilişkinin olmadığı birinci düzey modeli, bir başka deyişle 30 maddenin ilişkisiz beş farklı yapıyı ölçtüğünü temsil etmektedir. İlişkisiz-birinci düzey model, gözlenen değişkenlerin birbiriyle bağlantısız faktörler altında toplandığ1 modeldir. Model 3, ilişkili-birinci düzey, ölçekteki 30 maddenin ilişkili beş faktörü ölçtüğünü göstermektedir. İlişkili-birinci düzey, gözlenen değişkenlerin birbiriyle ilişkili faktörler altında toplandığ1 modeldir. İlişkili-birinci düzey model uyumunun olması ikinci düzey modellerin araştırılmasını gerekli kılmaktadır (Canivez, 2016).

Model 4, ikinci düzey DFA modelidir. İkinci düzey model, beş alt faktörün yordadığı bir üst seviye yapının modele dâhil edilmesidir. Bu modeldeki varsayım Mesleki Karar envanterindeki beş alt faktörün bir üst yapı olan Karar (Mesleki Karar) değişkenini oluşturduğudur. İkinci düzey modelde, karar faktörünün gözlenen göstergeler (maddeler) üzerindeki etkisi ise dolaylıdır.

Şekil 1'deki Model 5, iki-faktör/iki etkenli (bi-factor) modeli temsil etmektedir. İki-faktör modelde gözlenen değişkenleri hesaba katan genel bir faktör vardır. İki-faktör modelleri, belirli bir madde grubunun genel bir temel faktör ve grup düzeyinde faktörler tarafından açıklanma derecesini eşzamanlı olarak test etmek için bir seçenektir (Flores-Kanter, Dominguez-Lara, Trógolo ve Medrano, 2018). 


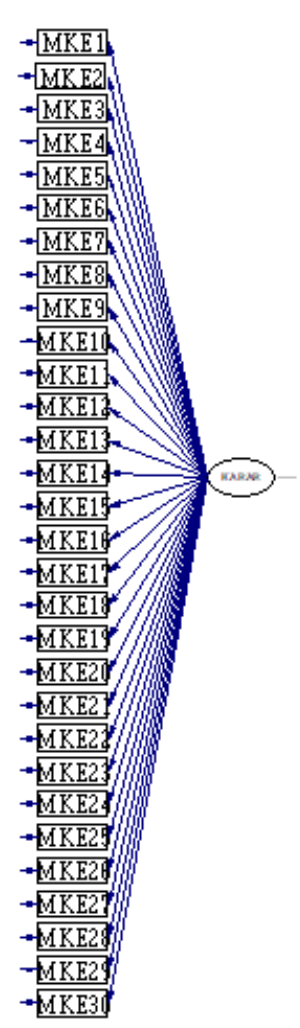

Model 1

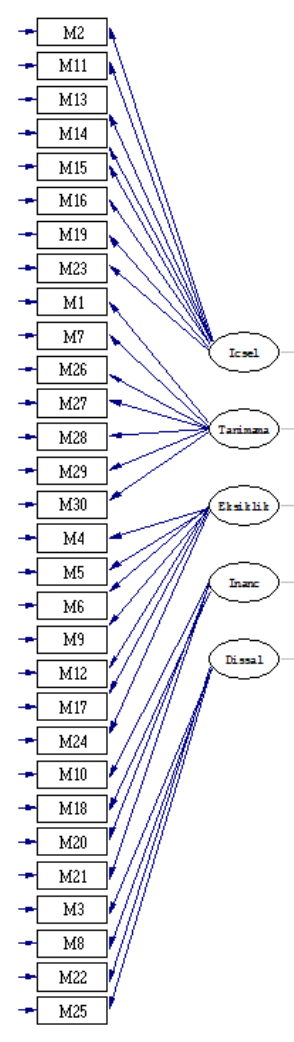

Model 2

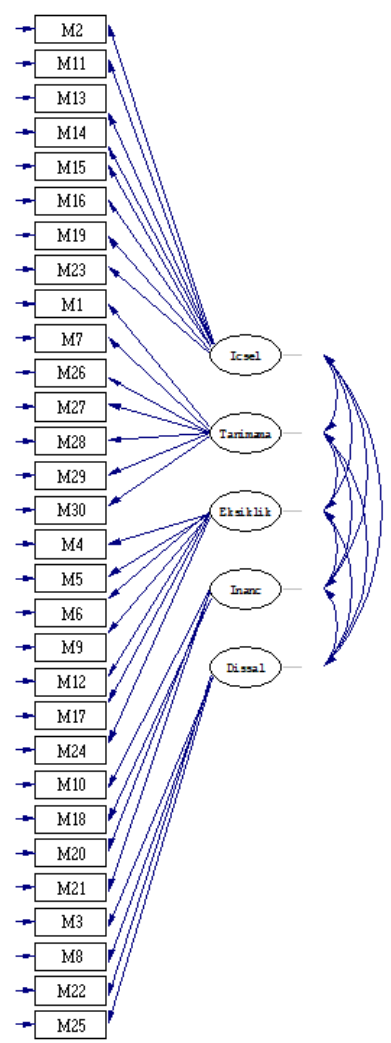

Model 3
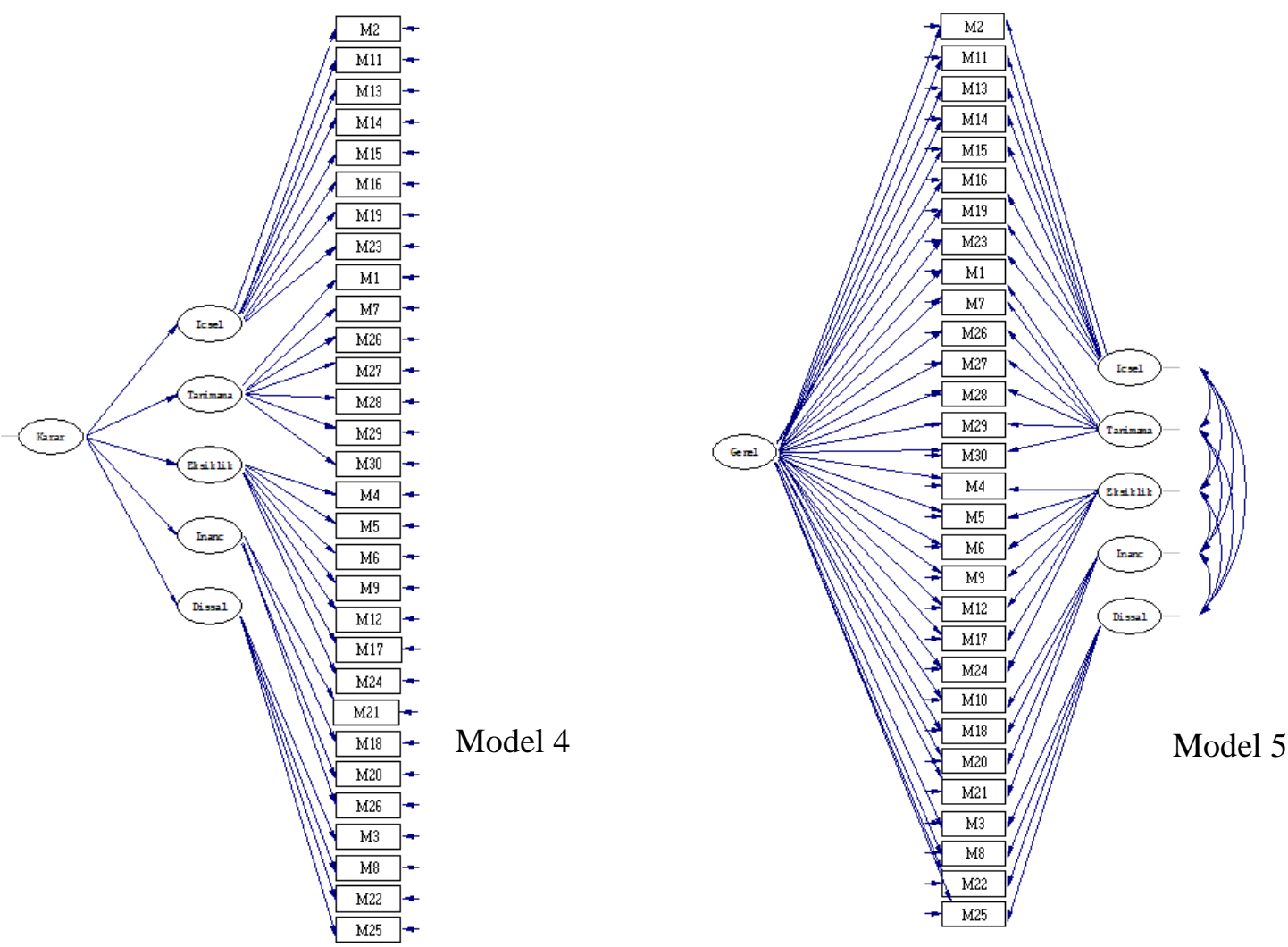

Şekil 1. Ölçme modelleri

Şekil 1'deki Model 5'te 30 maddenin tümü beş faktöre ek olarak genel bir faktöre de yüklenmiştir. Verilerin tek bir mesleki karar genel yapısı ve beş faktörle açıklanabileceği varsayılmıştır. Şekil 1'de verilen Model 5'teki iki- 
faktör model, hem güçlü genel bir karar faktörü hem de ilişkili alt faktörlerden oluşmaktadır. Genel faktör, envanter ile ölçülmek istenen yapıyı temsil ederken, alt faktörler bu yapıya ait alt alanları temsil etmektedir (Rodriguez, Reise ve Haviland, 2016).

İki-faktör ve ikinci düzey model birbiriyle ilişkili pek çok etki alanından oluşan genel yapıları temsil etmek için kullanılan iki alternatif yaklaşımdır (Chen, West ve Sousa, 2006). Aralarındaki farklılık, iki-faktör modelde genel faktörün gözlenen değişkenler üzerindeki doğrudan etkileri belirlenmiştir (Brown, 2015). İki-faktör model hem genel faktöre ilişkin etkileri açıklarken hem de alt faktörlerin etkilerini açıklamaktadır (Reise, 2012). İkinci düzey modelde grup düzeyindeki faktörler genel faktörü temsil ederken, iki-faktör modelde grup düzeyindeki faktörler bağımsız ve genel faktörün alt sıra faktörleri olmadığ 1 varsayılır (Flores-Kanter ve diğ., 2018). Buna bağlı olarak iki-faktör modelde, hem genel kurguyu hem de spesifik faktörleri ölçmeyi amaçlayan bir aracın geçerliliğini değerlendirmek için özellikle yararlıdır (Rodriguez ve diğerleri, 2016). İkinci düzey modelde genel faktör ölçülen değişkenleri dolaylı etkiler. Buna karşılık iki-faktör modelde genel faktör alt faktörlerden bağımsız olarak ölçülen her değişkeni doğrudan etkiler.

Şekil 1'de gösterilen modeller üzerinden envanterden elde edilen veri ile doğrulayıcı faktör analizi yapmadan önce veride uç değerler olup olmadığı kontrol edilmiştir. Veri setinde tek değişkenli uç değere rastlanmamıştır. Çok değişkenli uç değerlerde temizlenerek çalışma grubu oluşturulmuştur. Normallik varsayımı için öncelikle çarpıklık-basıklık katsayıları, Q-Q grafikleri incelenmiştir. Çarpıklık basıklık katsayılarına ve grafiğe göre bazı faktörler için dağılımın normalden sapma gösterdiği, bazı faktörlerin ise dağılımın normalden aşırı sapma göstermediği belirlenmiştir. Kolmogorov-Smirnov (K-S) testi sonuçlarına göre de normallik varsayımının bazı faktörler için sağlandığı belirlenmiştir (K-S=0,047, $\mathrm{p}>0,05 \mathrm{vb}$.). Tek değişkenli normalliğin sağlanması çok değişkenli normalliği garanti etmese de çok değişkenli normalliğin sağlanabilmesinin ön şartı tek değişkenli normallik varsayımının sağlanabilmesidir (Kline, 2016). Bu nedenle araştırmada normallik varsayımı gerektirmeyen Robust En Çok Olabilirlik kestirimi ve Satorra-Bentler ki-kare kullanılmıştır.

Araştırmada her bir modelden elde edilen model uyum indeksleri karşılaştırılmıştır. Litaratürde DFA'nde sıklıkla kullanılan model uyum indekslerinden Satorra-Bentler ki-kare ve serbestlik derecesi oranı ( $\chi 2 / \mathrm{sd})$, Hataların Ortalama Karekökü (RMSEA), Normlaştırılmamış Uyum İndeksi (NNFI-TLI) ve Karşılaştırmalı Uyum İndeksi (CFI) kullanılmıştır. Ayrıca çalışmada uyum indekslerinden, farklı modelleri karşılaştırmada ve model seçmede kullanılan Akaike Bilgi Kriteri (AIC) ve Beklenen Çapraz Geçerlilik İndeksi de (ECVI) kullanılmıştır.

Çalışmada modellerin veriye uygunluğunu belirlemek için kullanılan uyum indekslerinden $\chi 2 /$ sd değerinin 3 'den küçük olması mükemmel uyum, 5'den küçük olması ise orta düzeyde, kabul edilebilir uyumu göstermektedir (Kline, 2005; Sümer, 2000). RMSEA'nın 0,10'dan küçük olması zayıf uyum (Tabachnick ve Fidell, 2001), 0.08'den küçük olması kabul edilebilir uyum, 0.05'ten küçük olması mükemmel uyumu göstermektedir (Browne ve Cudeck, 1993 akt. Jöreskog ve Sörbom, 1993). CFI, TLI değerlerinin 0.90’dan büyük olması kabul edilebilir uyuma, 0.95 değerinden büyük olması ise mükemmel uyuma işaret etmektedir (Hooper, Coughlan ve Mullen, 2008; Hu ve Bentler, 1999; Schermelleh-Engel, Moosbrugger ve Müller, 2003; Sümer, 2000). Modellerin karşılaştırılmasında en küçük tahmin edilen AIC ve ECVI değerleri ise en iyi uyuma sahip modeli göstermektedir. Araştırmada ayrıca Mesleki Karar değişkenine ait ortalama açıklanan varyans (Average Variance Extracted, AVE) ve yapı güvenirliği (Construct Reliability, CR) de hesaplanmıştır. Araştırmadaki doğrulayıcı faktör analizlerini yapmada LISREL (8.72) programı kullanılmıştır.

\section{BULGULAR}

Araştırmada lise öğrencilerinin mesleki karar/kararsızlık durumlarını belirlemeye yönelik geliştirilen Mesleki Karar envanterinin yapısının doğrulanması amacıyla Şekil 1'de gösterilen farklı modeller oluşturulmuştur. Tablo 1 'de oluşturulan modellere ait uyum indeksleri verilmiştir.

Tablo 1'de uyum indeksleri test edilen modellerden, Model 1 tek boyut (one-factor model), Model 2 faktörler arasında ilişkinin olmadığı birinci düzey, Model 3 ilişkili-birinci düzey, Model 4 ikinci düzey (second order) ve Model 5 iki-faktör (bi-factor) ölçme modelini temsil etmektedir. 


\begin{tabular}{|c|c|c|c|c|c|c|}
\hline \multicolumn{7}{|c|}{ Uyum İndeksleri } \\
\hline & $\chi^{2} / \mathrm{sd}$ & RMSEA & CFI & TLI & AIC & ECVI \\
\hline$\overline{\text { Model } 1}$ & 4.56 & 0.087 & 0.92 & 0.92 & 1968.12 & 4.22 \\
\hline Model 2 & 4.69 & 0.089 & 0.92 & 0.92 & 2017.81 & 4.33 \\
\hline Model 3 & 2.23 & 0.051 & 0.97 & 0.97 & 1020.84 & 2.19 \\
\hline Model 4 & 2.16 & 0.050 & 0.98 & 0.97 & 991.65 & 2.13 \\
\hline Model 5 & 1.72 & 0.039 & 0.99 & 0.98 & 827.12 & 1.77 \\
\hline
\end{tabular}

Tablo 1'de verilen uyum indekslerine göre, Model 1'e ait uyum indeksleri zayıf uyumu göstermektedir. Bu durum 30 maddenin tek bir yapıyı ölçen modele (tek faktör) uymadı̆̆ını göstermektedir.

Tablo 1'deki, modeller arasından Model 2 en zayıf uyumu göstermektedir. Model 2 için elde edilen uyum indeksleri yeterli değildir. Bu durum 30 maddenin ilişkisiz beş farklı yapıyı ölçebileceğini doğrulamamaktadır. Ayrıca Model 2 ve 3 ölçeğin birbiriyle ilişkisiz ve ilişkili beş faktör yapılarını temsil etmektedir. Model 3'e ait uyum indeksleri incelendiğinde elde edilen uyum indekslerinin iyi/mükemmel olduğu görülmektedir. Ayrıca Model 3'e ait uyum indeksleri Model 2'ye göre daha iyi bulunmuştur. Bu doğrultuda 30 maddenin oluşturduğu beş faktörün birbiriyle ilişkili yapıyı ölçmeye daha uygun olduğunu söylemek mümkündür. Model 2'ye göre Model 3'e ait uyum indekslerinin daha iyi çıkması faktörler arası korelasyonun olduğuna işaret etmektedir. Bu doğrultuda Canivez (2016), ilişkili birinci düzey modeli hesaba katan ikinci düzey ve iki-faktör modellerinin de incelenmesini önermektedir.

Model 4 ikinci düzey DFA sonuçlarını göstermektedir. İçsel Çatışmalar (İçsel), Kendini Yeterince Tanımama (Tanımama), Meslek ve Alan Bilgisi Eksikliği (Eksiklik), Meslek Seçimine İlişkin Akılcı Olmayan İnançlar (İnanç) ve Dişsal Çatışmalar (Dişsal) değişkenlerinin Mesleki Karar değişkenini oluşturduğunu ifade etmektedir. Model 4'e ait uyum indeksleri mükemmel düzeydedir. Ayrıca Model 4'e ait uyum indekslerinin ilk üç modele göre daha iyi olduğu görülmektedir.

Model 5'e ait uyum indekslerinin mükemmel uyum gösterdiği söylenebilir. Tablo 1'de verilen uyum indekslerine göre, Mesleki Karar envanterinin faktör yapısı en iyi Model 5'te daha sonra ise Model 4'te en iyi uyumu göstermektedir. Tablo 1'de verilen AIC ve ECVI değerleri de en iyi 5., daha sonra ise 4. modelin diğer modellerden daha iyi olduğunu doğrulamaktadır. Literatürde iki-faktör modelin (Model 5) ikinci düzey modele (Model 4) göre çoğunlukla daha iyi uyum gösterdiği belirtilmiştir (Beaujean, Parkin ve Parker, 2014; Benson, Hulac ve Bernstein, 2013; Gignac, 2008, 2016; Gignac ve Watkins, 2013; Murray ve Johnson, 2013; Reise, Kim, Mansolf ve Widaman, 2016; Watkins, 2010). Bu nedenle ölçme modelini doğrulamada uyum indekslerinin yanında model göstergeleri de dikkate alınarak karar verilmelidir (Flores-Kanter ve diğ., 2018).

Modellere ait uyum indekslerinin karşılaştırılması sonucunda Mesleki Karar Envanteri maddelerinin en iyi ikifaktör, daha sonra ise ikinci düzey modelde uyum gösterdiği belirlenmiştir. Bu iki modele ait $t$ değerlerinin manidarlığı incelendiğinde, iki-faktör ölçme modelinde bazı maddelere $(1,6,7,11$ ve 19) ait $t$ değerleri anlamlı bulunmamıştır. İkinci düzey modeldeki t değerleri ise 6.13 ile 13.36 arasında değişmektedir. İkinci düzey ölçme modelinin doğrulayıc faktör analizi sonucunda envanterdeki tüm maddelere ait $t$ değerleri 0.01 düzeyinde anlamlı bulunmuştur. Bu doğrultuda ikinci düzey modelin veriye daha uygun olduğunu söylemek mümkündür. İkinci düzey DFA sonuçlarına göre genel yapı olan Mesleki Karar üzerinde en çok etkiye sahip değiş̧ken Meslek ve Alan Bilgisi Eksikliği (0.84) ve en az etkiye sahip değişken ise Dışsal Çatışmalardır $(0,72)$.

İkinci düzey modelin kabulünden sonra, bu modelden elde edilen faktör yükü ve hata varyanslarından hareketle Mesleki Karar değişkenine ait ortalama açıklanan varyans (Average Variance Extracted, AVE) ve yapı güvenirliği (Construct Reliability, CR) değerleri hesaplanmıştır. Bu değerler Tablo 2'de verilmiş̧tir.

Tablo 2.

Ortalama Açıklanan Varyans ve Yapı Güvenirliği

\begin{tabular}{lcc}
\hline & Ortalama Açıklanan Varyans & Yapı Güvenirliği \\
\hline Mesleki Karar & 0.64 & 0.90 \\
\hline
\end{tabular}

Yapı güvenirliği, faktör yükleri ve hata varyansları ile birlikte yapısal eşitlik modelleri ile birlikte kullanılmaktadır (Hair, Black, Babin ve Anderson, 2014). Yapı güvenirliği, gizil bir yapıyı temsil eden değişkenler için iç tutarlılık ve güvenirlik ölçüsü olarak tanımlanmıştır (Hair ve ark.,, 2014).

Tablo 2'de gösterildiği gibi Mesleki Karar değişkenine ait ortalama açıklanan varyans 0,64 ve yapı güvenirliği ise 0,90 olarak hesaplanmıştır. Hair ve ark. (2014), ortalama açıklanan varyansın en az 0,50 ve yapı güvenirliğinin ise en az 0,70 olmasını önermektedir. Bu doğrultuda envantere ait ortalama açıklanan varyans ve yapı güvenirliği 
değerlerinin yeterli olduğu söylenebilir. Ayrıca Hair ve ark. (2014), yüksek yapı güvenirliğini iç tutarlığın bir ölçüsü, yani ölçümlerin aynı gizil yapıyı temsil etmesi olarak belirtmektedir. Bu doğrultuda envanter için elde edilen yüksek yapı güvenirliği iç tutarlığında olduğunu göstermektedir. Buradan hareketle mesleki karar envanterine ait ölçümlerin (measures) aynı gizil yapıyı temsil ettiği de söylenilebilir.

\section{TARTIŞMA ve SONUÇ}

Araştırmada, Mesleki Karar envanterinin 5 faktör toplam 30 madde içeren formu ile ortaya konulan yapı tek boyut, birinci düzey, ilişkisiz birinci düzey, ikinci düzey ve iki-faktör model olmak üzere 5 farklı model çerçevesinde doğrulayıcı faktör analizi ile test edilmiştir. Yapılan doğrulayıcı faktör analizlerinde, Mesleki Karar Envanterinin ikinci düzey yapısının bir model olarak doğrulandığı sonucuna ulaşılmıştır. Bu doğrultuda, Mesleki Karar envanterinde yer alan 5 alt faktörün tek bir mesleki karar genel yapısını oluşturduğu söylenilebilir. Bir başka deyişle, İçsel Çatışma, Kendini Yeterince Tanımama, Meslek ve Alan Bilgisi Eksikliği, Meslek Seçiminde Akılcı Olmayan İnançlar ve Dışsal Çatışmalar değişkenlerinin üst düzey örtük bir değişken olan Mesleki Karar değişkeni tarafından açıklandığı belirlenmiştir. Mesleki Karar envanterinin "İçsel Çatışmalar", "Kendini Yeterince Tanımama", "Meslek ve Alan Bilgisi Eksikliği", "Meslek Seçimine İlişkin Akılcı Olmayan İnançlar" ve "Dışsal Çatışmalar" alt faktörleri ayrı ayrı ele alınabileceği gibi mesleki karar değişkenine ilişkin bir puan da elde edilebileceğini söylemek mümkündür. Bunlarla birlikte Mesleki Karar değişkeni üzerinde en çok etkiye sahip değişkenin Meslek ve Alan Bilgisi Eksikliği olduğu belirlenmiştir. Bu doğrultuda meslekler ve eğitim görülecek alanla ilgili yapılacak mesleki rehberlik çalışmalarının mesleki kararsızlığı azaltmada önemli olduğu söylenilebilir. Steward (1995), meslek danışmanlarının danışanlarında mesleklerle ilgili bilgi eksikliği durumu ile sıklıkla karşılaşıldığını belirtmektedir. Bununla birlikte Gati (1986), mesleki kararsızlık üzerindeki bir etkinin mesleki karar verme sürecindeki bilgi eksikliği olduğunu belirtmektedir. Buradan da bilgi eksikliğinin mesleki kararkararsızlık durumunu etkileyebileceği görülmektedir. Bireyin bilmediği bir durumla ilgili tercih yaparken kararsızlık yaşaması olasıdır.

Envanterin yapı geçerliğine ilişkin kanıtlardan ve araştırma verilerinden elde edilen güvenirlik katsayılarına bakılarak Mesleki Karar envanterinin lise öğrencilerinin mesleki karar-karasızlık durumlarını belirlemeye yönelik kullanılabilecek bir ölçme aracı olduğu söylenilebilir. Ayrıca envanterdeki alt ölçek puanlarıyla içsel çatışmalar, kendini yeterince tanımama, meslek ve alan bilgisi eksikliği, meslek seçimine ilişkin akılcı olmayan inançlar ve dışsal çatışmalar nedeniyle yaşanılan kararsızlık düzeyleri de ölçülebilir.

Mesleki karar envanterinin geçerlik kanıtlarını artırmak için bir başka çalışmada öğrencilerin mesleki karar verme ölçüt durumlarına bağlı geçerlilik çalışması yapılabilir. Ayrıca mesleki karar durumu ile ilişkili başka yapılar ele alınarak envanterin yapı geçerliği ek kanıtları araştırılabilir. 


\section{KAYNAKÇA}

Alpar, R. (2017). Uygulamalı çok değişkenli istatistiksel yöntemler. Ankara: Detay Yayıncılık.

Beaujean, A.A., Parkin, J., \& Parker, S. (2014). Comparing Cattell-Horn-Carroll factor models: Differences between bifactor and higher order factor models in predicting language achievement. Psychological. Assessment, 26(3), 789-805.

Benson, N., Hulac, D.M., \& Bernstein, J.D. (2013). An independent confirmatory factor analysis of the Wechsler Intelligence Scale for Children-Fourth Edition (WISC-IV) Integrated: What do the process approach subtests measure? Psychological Assessment, 25(3), 692-705.

Bentler, P. M., \& Chou, C. P. (1987). Practical issues in structural equation modeling. Sociological Methods and Research, 16(1), 78-117.

Boomsma, A., \& Hoogland, J. J. (2001). The robustness of LISREL modeling revisited. In R. Cudeck, S. du Toit, \& D. Sörbom (Eds.), Structural equation models: Present and future. A Festschrift in honor of Karl Jöreskog (pp. 139-168), Chicago: Scientific Software.

Brown, T. A. (2015). Confirmatory factor analysis for applied research. New York: The Guilford Press.

Byrne, B. M. (1998). Structural equation modelling with LISREL, PRELIS, and SIMPLIS: basic concepts, applications, and programming. Mahwah, NJ: L. Erlbaum.

Canivez, G. L. (2016). Bifactor modeling in construct validation of multifactored tests: Implications for multidimensionality and test interpretation. In K. Schweizer \& C. DiStefano (Eds.), Principles and methods of test construction: Standards and recent advancements (pp. 247-271). Gottingen, Germany: Hogrefe.

Cucina, J., \& Byle, K. (2017). The bifactor model fits better than the higher-order model in more than $90 \%$ of comparisons for mental abilities test batteries. Journal of Intelligence, 5(3), 27.

Çakir, M. A. (2004). Mesleki karar envanterinin geliştirilmesi [The development of career decision inventory]. Ankara Üniversitesi Ĕ̈itim Bilimleri Fakültesi Dergisi, 37(2), 1-14.

Flores-Kanter, P. E., Dominguez-Lara, S., Trógolo, M. A., \& Medrano, L. A. (2018). Best practices in the use of bifactor models: Conceptual grounds, fit indices and complementary indicators. Revista Evaluar, 18(3), 44-48. Retrieved March 15, 2019 from https://revistas.unc.edu.ar/index.php/revaluar

Gati, I. (1986). Making carer decisions: A sequential elimination approach. Journal of Counselling Psychology, 33(4), 408-417.

Gignac, G. E. (2008). Higher-order models versus direct hierarchical models: g as superordinate or breadth factor? Psychology Science, 50(1), 21-43.

Gignac, G.E. (2016). The higher-order model imposes a proportionality constraint: That is why the bifactor model tends to fit better. Intelligence, 55, 57-68.

Gignac, G.E., \& Watkins, M.W. (2013). Bifactor modeling and the estimation of model-based reliability in the WAIS-IV. Multivariate Behavioral Research, 48(5), 639-662.

Hair, J.F., Black, W. C., Barry, J.B., \& Anderson, R.E. (2014). Multivariate data analysis. (Seventh edition, Pearson new international edition). Harlow: Pearson Education Limited.

Hooper, D., Coughlan, J., \& Mullen, M. (2008). Structural equation modeling: quidelines for determining model fit. Electronic Journal of Business Research Methods, 6(1), 53-60.

Hu, L.T., \& Bentler, P. M. (1999). Cutoff criteria for fit indexes in covariance structure analysis: Conventional criteria versus new alternatives. Structural Equation Modeling: A Multidisciplinary Journal, 6(1), 1-55. http:1/doi.org/10.1080/10705519909540118

Jackson, D. L. (2001). Sample size and number of parameter estimates in maximum likelihood confirmatory factor analysis: A Monte Carlo investigation. Structural Equation Modeling, 8(2), 205-223.

Jöreskog, K., \& Sörbom, D. (1993). LISREL 8: Structural equation modeling with the SIMPLIS command language. Chicago, IL: Scientific Software International Inc.

Kline, B.R. (2005, 2016). Principles and practice of structural modeling. New York-London: The Guilford Press.

Meydan, C. H. \& Şeşen, H. (2015). Yapısal eşitlik modellemesi AMOS uygulamaları. Ankara: Seçkin Yayıncılık.

Moshagen, M., \& Musch, J. (2014). Sample size requirements of the robust weighted least squares estimator. Methodology, 10(2), 60-70.

Murray, A. L., \& Johnson, W. (2013). The limitations of model fit in comparing the bi-factor versus higher-order models of human cognitive ability structure. Intelligence, 41(5), 407-422.

Worthington, R. L., \& Whittaker, T. A. (2006). Scale development research: A content analysis and recommendations for best practices. The Counseling Psychologist, 34(6), 806-838.

Reise, S. P. (2012). The rediscovery of bifactor measurement models. Multivariate Behavioral Research, 47(5), 667-696. http://dx.doi.org/10 .1080/00273171.2012.715555

Reise, S. P., Kim, K. H., Mansolf, M., \& Widaman, K. F. (2016). Is the bifactor model a better model or is it just better at modeling implausible responses? Application of iteratively reweighted least squares to the Rosenberg Self- Esteem Scale. Multivariate Behavioral Research, 51(6), 818-838. 
Rodriguez, A., Reise, S. P., \& Haviland, M. G. (2016). Applying bifactor statistical indices in the evaluation of psychological measures. Journal of Personality Assessment, 98(3), 223-237. doi: 10.1080/00223891.2015.1089249

Schermelleh-Engel, K., Moosbrugger, H., \& Müller, H., (2003). Evaluating the fit of structural equation models: Test of significance and descriptive goodness-of-fit measures. Methods of Psychological Research Online, 8(2), 23-74.

Sümer, N. (2000). Yapısal eşitlik modelleri: Temel kavramlar ve örnek uygulamalar. Türk Psikoloji Yazıları, 3(6), 49-74.

Steward, J. (1995). Counseling individuals who experience career decision-making diffuculties. Guidance \& Counseling, 10(4), 52-55.

Şimşek, Ö.F. (2007). Yapısal eşitlik modellemesine giriş: Temel ilkeler ve LISREL uygulamalarl. Ankara: Ekinoks Yayınlar1.

Tabachnick, B.G., \& Fidell, L.S. (2001). Using multivariate statistics. New York: Allyn \&Bacon Inc.

Watkins, M. W. (2010). Structure of the Wechsler Intelligence Scale for Children-fourth edition among a national sample of referred students. Psychological Assessment, 22(4), 782-787. 


\section{EXTENDED ABSTRACT}

\section{Introduction}

Factor analysis is frequently used in order to reveal the structure of the measurement tool and data and to present a road map to the researcher in education and psychology. In the literature, it is recommended to examine the structure of the scales with confirmatory factor analysis, and even compare different models and determine the most appropriate model for the data (Byrne, 1998; Cucina ve Byle, 2017; Meydan ve Şeşen, 2015). However, it is seen that the first level DFA model is frequently tested in scale development studies in the literature. As a requirement of scientific research, evidence should be provided on which model is produced by the best explanation for these variables (Şimşek, 2007).

In the research Career Decision Inventory (CDI) developed by Çakır (2004) was used. The inventory is one of the important tools that can be used to determine the professional instability of high school students. Exploratory factor analysis was used by Çakır (2004) to determine the factor structure in the development phase of the inventory. In this study, the factor structure of the inventory was analyzed with confirmatory factor analysis with the data obtained from a different group from the development stage of the inventory within the framework of different models established in line with the factor analysis of the researcher and the results were discussed. In this direction, it is aimed to test the factor structure of Career Decision Inventory with confirmatory factor analysis in addition to exploratory factor analysis and to determine the most suitable model. In this study, the structure revealed in the preliminary study was tested with confirmatory factor analysis in five different models: unidimensional, correlated first-order, uncorrelated first-order, second-order and bifactor model.

\section{Method}

The research was conducted on the data obtained from 467 students in high schools in Nevşehir city center. The students participated in the study were in the 11th and 12th grades and their ages ranged between 16-18. Career Decision Inventory (CDI) is used to investigate the vocational decision status of high school students. CDI, "Internal Conflicts”, "Lack of Self Knowledge”, “Lack of Occupation and Field Knowledge”, “Irrational Beliefs about Career Choice" and "External Conflicts" consists of five factors. There are 30 items in the inventory. In the study conducted by Çakır (2004), in the development phase of the inventory, there are 8 items in the internal conflicts factor, 7 items lack of self-knowledge, 7 items lack of occupational and field knowledge, 4 items irrational beliefs about career choice and 4 items in external conflicts. The items are answered in 5-point Likert format. The high score obtained from the inventory indicates the career indecision of the students.

Cronbach's alpha reliability coefficient was 0.85 and test-retest reliability was 0.83 during the development of the inventory (Çakır, 2004). In this study, the Cronbach's alpha reliability coefficient of the inventory was calculated as 0.93 for inventory, 0.87 for internal conflict, 0.81 for lack of self knowledge, 0.80 for lack of occupation and field knowledge, 0.70 for irrational beliefs about career choice and 0.70 for the external conflicts factor.

In this study, model fit indexes (Satorra-Bentler $\chi 2 / \mathrm{df}$, RMSEA, TLI, CFI, AIC, ECVI) obtained from each model were compared. And, in the study, the Average Variance Extracted (AVE) and Construct Reliability (CR) of the Career Decision variable were also calculated. LISREL (8.72) program was used for confirmatory factor analysis.

\section{Findings, Discussion and Results}

Different models have been tested in order to verify the structure of the Career Decision Inventory developed to determine the career decision/indecision status of high school students. The uncorrelated first level model of the tested models did not show model fit. When the indices of the correlated first-order model were examined, it was determined that the model fit indices obtained were acceptable. In this respect, it is possible to say that the five factors composed of 30 items are more suitable for measuring the interrelated structure. After this result indicating second level and bi-factor models were also examined. The fit indexes of the second level model were acceptable level. And the factor structure of the Career Decision Inventory was found to be the best fit in the bi-factor model and then in the second level model. In the literature, it is stated that bi-factor model can mostly adapt better than second level model (Beaujean, Parkin ve Parker, 2014; Benson, Hulac ve Bernstein, 2013; Gignac, 2008, 2016; Gignac ve Watkins, 2013; Murray ve Johnson, 2013; Reise, Kim, Mansolf ve Widaman, 2016; Watkins, 2010). For this reason, in order to validate the measurement model, bi-factor model indicators should be taken into consideration in addition to model-fit indexes (Flores-Kanter et al., 2018). When the significance of $t$ values of the models was examined, $t$ values of some items were not found significant in the bi-factor measurement model. As a result of confirmatory factor analysis of second level measurement model, $t$ values of all items in the inventory were found to be significant at 0.01 level. In this respect, it can be said that the second level model is more appropriate to the data. After the adoption of the second level model, the average variance extracted (AVE) and 
Construct Reliability (CR) values of the Professional Decision variable were also calculated. The average variance extracted was calculated as 0.64 and the construct reliability was calculated as 0.90 . Hair, Black, Babin and Anderson (2014) suggest that the average variance extracted is at least 0.50 and the construct reliability is at least 0.70 . In this respect, it can be said that the average variance extracted and construct reliability values of the inventory are sufficient.

As a result, in the confirmatory factor analysis, it was concluded that the second-order structure of the Career Decision Inventory was confirmed as a model. In this direction, it can be said that the variables of (1) Internal Conflicts, (2) Lack of Self Knowledge, (3) Lack of Occupation and Field Knowledge, (4) Irrational Beliefs about Career Choice and (5) External Conflicts constitute the Career Decision Structure. It can be said that the Career Decision Inventory is a measurement tool that can be used to determine the Professional-career decision-making status of high school students. 